\title{
Morphological and molecular characterization of Karyolysus - a neglected but common parasite infecting some European lizards
}

Božena Haklová-Kočíková ${ }^{1}$ Adriana Hižňanová2 ${ }^{2}$ Igor Majláth ${ }^{1,2}$, Karol Račka ${ }^{3}$, David James Harris ${ }^{4}$, Gábor Földvári ${ }^{5}$, Piotr Tryjanowski ${ }^{6}$, Natália Kokošová ${ }^{2}$ Beáta Malčeková7 and Viktória Majláthová ${ }^{*}$

\begin{abstract}
Background: Blood parasites of the genus Karyolysus Labbé, 1894 (Apicomplexa: Adeleida: Karyolysidae) represent the protozoan haemogregarines found in various genera of lizards, including Lacerta, Podarcis, Darevskia (Lacertidae) and Mabouia (Scincidae). The vectors of parasites are gamasid mites from the genus Ophionyssus.

Methods: A total of 557 individuals of lacertid lizards were captured in four different localities in Europe (Hungary, Poland, Romania and Slovakia) and blood was collected. Samples were examined using both microscopic and molecular methods, and phylogenetic relationships of all isolates of Karyolysus sp. were assessed for the first time. Karyolysus sp. 18S rRNA isolates were evaluated using Bayesian and Maximum Likelihood analyses.

Results: A total of 520 blood smears were examined microscopically and unicellular protozoan parasites were found in 116 samples (22.3\% prevalence). The presence of two Karyolysus species, K. latus and K. lacazei was identified. In total, of 210 samples tested by polymerase chain reaction (PCR), the presence of parasites was observed in 64 individuals (prevalence 30.5\%). Results of phylogenetic analyses revealed the existence of four haplotypes, all part of the same lineage, with other parasites identified as belonging to the genus Hepatozoon.

Conclusions: Classification of these parasites using current taxonomy is complex - they were identified in both mites and ticks that typically are considered to host Karyolysus and Hepatozoon respectively. Furthermore although distortions to the intermediate host erythrocyte nuclei were observed, the defining characteristic of Karyolysus, the haplotypes were nearly identical to those reported from lizards in the Iberian Peninsula, where such distortions were not reported and which were thus identified as Hepatozoon. Based on the phylogenetic analyses, neither vertebrate host, nor geographical patterns of the studied blood parasites could be established.
\end{abstract}

Keywords: Karyolysus, Ophionyssus, Lacertidae, lizards, Europe

\section{Background}

Reptiles often serve as hosts for unicellular blood parasites belonging to the suborder Adeleorina, mainly from the genera Haemogregarina, Hepatozoon and Karyolysus. Haemogregarina was found in various species of terrapins, while Hepatozoon is the typical apicomplexan parasites found in different species of snakes and lizards [1], each distinguished by very different developmental patterns in their invertebrate hosts in which sporogony occurs. To

\footnotetext{
* Correspondence: majlat@saske.sk

${ }^{1}$ Institute of Parasitology, Slovak Academy of Sciences, Hlinkova 3, 04001 Košice, Slovak Republic

Full list of author information is available at the end of the article
}

date, Karyolysus has been reported mainly in European lizards [2-5], as well as in Asia [6]. The genus Karyolysus Labbé 1894 includes ten currently recognized species: K. lacertae Danilewsky, 1886, K. lacazei Labbé, 1894, K. biretortus Nicolle, 1904, K. berestnewi Finkelstein, 1907, K. bicapsulatus Franca, 1910, K. zuluetai Reichenow, 1920, K. subtilis Ricci, 1954, K. octocromosomi Alvarez-Calvo, 1975, K. latus Svahn, 1975 and K. minor Svahn, 1975.

The life cycle of Karyolysus sp. is indirect; merogony occurs in an intermediate vertebrate host, while gamogony and sporogony takes place in the gut of an invertebrate final host [1]. Gamasid mites Ophionyssus sp. Oudemans, 1901, belonging to the order Mesostigmata, act as the 
main vectors. These are strictly obligate parasites and can utilize hosts that are taxonomically related (lizards, snakes) $[7,8]$. Karyolysus transmission to the lizard is thought to involve swallowing mites containing infectious sporozoites, without typical sporocystic arrangements. Meronts can be observed in capillary endothelium of the liver, lungs, heart, and spleen, while gamonts parasitize erythrocytes in peripheral blood of lizards [1,4]. While Hepatozoon is transmitted by a wide spectrum of invertebrates, including hard ticks, transmission of Karyolysus sp. from infected sand lizard (Lacerta agilis) to larvae and nymphs of Ixodes ricinus ticks was not experimentally demonstrated [4], although ticks on these lizards are more abundant than mites [9]. Karyolysus represent well defined group different in morphology and in life cycle, it differs from the closely related genera Hepatozoon and Hemolivia in several characteristics of its biology. In the life cycle, motile sporokinetes are formed in oocyst by a single germinal center and are released in host organism and encyst as sporocyst in Karyolysus. The genus Hepatozoon is characterized by a large polysporocystic oocyst. Intraerytrocytic merogony occurs in Hemolivia, moreover gamonts in the peripheral blood have typical morphology with the presence of a stain-resistant vacuole.

Although Karyolysus includes ten known species, only few authors classified parasites found in lizards to the species level [2-5]. Information about morphometry and morphology of few Karyolysus species are available [10], and species determination is very difficult and ambiguous: moreover measurements of cell size and area ratios may be modified due to alternative preparations of blood smears [3]. Therefore several authors classified detected parasites only as "haemogregarines" or "blood parasites" [9,11-14]. The presence of blood parasites was detected in various European lizards including Algyroides nigropunctatus, Iberolacerta horvathi, Podarcis muralis and P. melisellensis from Austria and Croatia [3], Podarcis lilfordi from Balearic Islands [11], L. agilis and Zootoca vivipara from Poland, Denmark and Sweden $[4,5,9]$, L. viridis from Hungary [15], Podarcis bocagei and Podarcis carbonelli from Portugal [16], L. agilis chersonensis from Romania [2] and Iberolacerta monticola, P. muralis and Timon lepidus from Spain [12-14].

Molecular data of parasites found in erythrocytes of European lizards are scarce. Only a few publications exist where molecular method were used to detect blood parasites in European lizards (Algyroides marchi, P. bocagei, $P$. hispanica and $P$. lilfordi); using phylogenetic analysis parasites from these hosts were identified as Hepatozoon sp., since they were nested within this group and since little or no distortion of the vertebrate host erythrocyte nucleus was observed, the defining characteristic of Karyolysus [17,18]. Molecular data of Karyolysus are not available in GenBank and the phylogenetic position of this genus in comparison to other reptile parasites is not known yet. Therefore it is necessary to obtain molecular data of Karyolysus, not only from lizards but also from Ophionyssus sp. mites, which are the only known vector of this parasite. Karyolysus parasites are neglected in molecular and phylogenetic analyses. More molecular data are available for Hemolivia, however the phylogenetic position of the genus remains unclear [19-21].

To summarize, the aim of the present study was to detect the presence of Karyolysus sp. in lizards and their ectoparasites, and to determine the taxonomy and phylogenetic relationship of parasites in various species of lizards from several regions of Europe (Hungary, Poland, Romania and Slovakia) using both molecular and microscopic examination methods. In this way we aim to test if different genetic lineages of parasites occur in various regions in Europe, since considerable diversity has been identified in blood parasites in other reptiles from this region [22].

\section{Methods}

Study areas

Biological samples from lizards were collected during field expeditions, which were undertaken in four countries in Europe (Poland, Hungary, Romania and Slovakia) (Figure 1, Table 1). Field trips were carried out from 2004 to 2013.

The first locality was near the town of Odolanów, Poland $\left(51^{\circ} 34^{\prime} \mathrm{N}, 17^{\circ} 40^{\prime} \mathrm{E}\right)$. This area is characterized by intensively farmed land with a mosaic of arable fields, meadows, and small woodlots and scattered trees and shrubs of different age.

The second locality is in Hungary near the town of Gödöllő $\left(47^{\circ} 36^{\prime} \mathrm{N}, 19^{\circ} 22^{\prime} \mathrm{E}\right)$ and the mountain Pilis $\left(47^{\circ} 41^{\prime} \mathrm{N}, 18^{\circ} 52^{\prime} \mathrm{E}\right)$. These localities are characteristic by maple oak and lime oak callow forests with bushes separated by less-covered moorlands; stone-pit, shady groves, protected natural values as well as in the south and in the east part of area vineyards are very common.

Reptiles in Romania were captured in various areas including Sâcele $\left(45^{\circ} 37^{\prime} \mathrm{N}, 25^{\circ} 42^{\prime} \mathrm{E}\right)$ typically by abandoned irrigation canals as a part of the steppe biogeographical region; Vadu $\left(44^{\circ} 26^{\prime} \mathrm{N}, 28^{\circ} 44^{\prime} \mathrm{E}\right)$ with vegetation represented by perennial shrubs, tall grass and species of rush (Juncus sp.), reed (Phragmites sp.) and bulrush (Typha sp.); Lepşa $\left(45^{\circ} 56^{\prime} \mathrm{N}, 26^{\circ} 34^{\prime} \mathrm{E}\right)$ situated in the valley of Lepșa river, where vegetation is represented by hydrophilous tall herb fringe communities, alluvial groves with Alnus sp. and patches of grass; Babadag $\left(44^{\circ} 53^{\prime} \mathrm{N}\right.$, $28^{\circ} 20^{\prime} \mathrm{E}$ ) located on a small lake formed by the Taița river, in the densely wooded highlands of northern Dobruja; Deniz Tepe $\left(44^{\circ} 59^{\prime} \mathrm{N}, 28^{\circ} 41^{\prime} \mathrm{E}\right)$, locality which is represent by hill at an elevation of 163 meters above sea level and Vrancea $\left(45^{\circ} 48^{\prime} \mathrm{N}, 27^{\circ} 04^{\prime} \mathrm{E}\right)$, seismically active area, over $11 \%$ of the country surface covered with vine and located in elevation of 170 meters above sea level. 


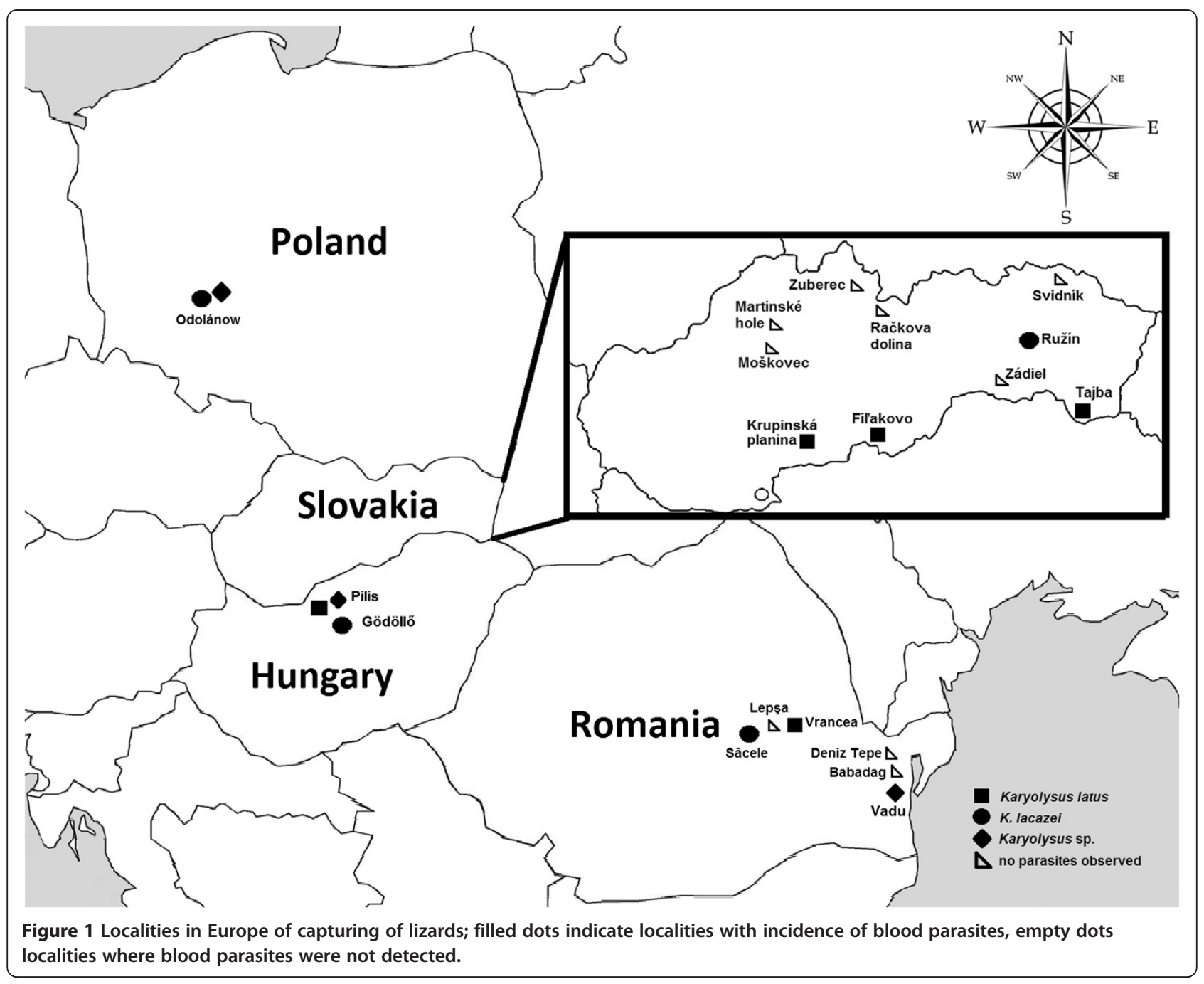

Finally, in Slovakia lizards were captured in various habitats including bog communities (Tajba, $48^{\circ} 26^{\prime} \mathrm{N}, 21^{\circ} 46^{\prime} \mathrm{E}$ ), mountain areas (Zuberec $49^{\circ} 18^{\prime} \mathrm{N}, 19^{\circ} 36^{\prime} \mathrm{E}$; Martinské hole $49^{\circ} 08^{\prime} \mathrm{N}, 18^{\circ} 49^{\prime} \mathrm{E}$; Račkova dolina $49^{\circ} 05^{\prime} \mathrm{N}, 19^{\circ} 47^{\prime} \mathrm{E}$; Moškovec $48^{\circ} 59^{\prime} \mathrm{N}, 18^{\circ} 49^{\prime} \mathrm{E}$ ), castle ruins (Filakovo $48^{\circ}$ $15^{\prime} \mathrm{N}, 19^{\circ} 49^{\prime} \mathrm{E}$ ), areas near the water basin (Ružín $48^{\circ} 55^{\prime} \mathrm{N}$, $21^{\circ} 02^{\prime} \mathrm{E}$ ), xerothermous karst areas (Zádiel $48^{\circ} 39^{\prime} \mathrm{N}, 20^{\circ}$ $56^{\prime} \mathrm{E}$ ), xerothermous areas of volcanic origin (Burda $47^{\circ}$ $52^{\prime} \mathrm{N}, 18^{\circ} 54^{\prime} \mathrm{E}$ and Krupinská planina $48^{\circ} 13^{\prime} \mathrm{N}, 19^{\circ} 05^{\prime} \mathrm{E}$ ) as well as peripheral areas of city agglomeration (Svidník $49^{\circ}$ $\left.20^{\prime} \mathrm{N}, 21^{\circ} 33^{\prime} \mathrm{E}\right)$.

\section{Sample collection}

Lizards were captured by noosing or by hand. Blood from lizards was taken via a ventral puncture of the vena coccygea. Blood for molecular analysis was stored in tubes with sodium citrate. In case of tail loss, tail tips were stored in $70 \%$ ethanol.

Ticks and mites were collected from lizards immediately in the field and stored in $70 \%$ ethanol. Some individuals were kept in white linen bags during the night. In the morning, engorged mites had left the lizards and were collected from the bags. Animals captured in the field were released after sampling at the capture place. The mites were kept in test-tubes in the laboratory $\left(23^{\circ} \mathrm{C}\right.$, $80 \%$ air humidity).

\section{Slide examination}

Smears from mites and their eggs were performed in the laboratory, air dried, fixed with methanol and stained with a Giemsa solution (30 minutes) and evaluated under a light microscope.

Blood smears from lizards were made and air-dried immediately in the field. In the laboratory staining was performed using May-Grünwald (10 minutes) and Giemsa solution (30 minutes) and examined with a light microscope at $\times 400$ magnifications. Approximately 50 microscopic fields on each smear were examined for the presence of blood parasites. When no parasites were detected by this method, the smear was considered 
Table 1 Lizard species examined in this study

\begin{tabular}{|c|c|c|c|c|c|c|}
\hline Species & Country & Study area & $\begin{array}{l}\text { Captured } \\
\text { individuals }\end{array}$ & $\begin{array}{l}\text { Microscopy } \\
\text { examined/infected }\end{array}$ & PCR examined/infected & $\begin{array}{l}\text { Species of } \\
\text { Karyolysus }\end{array}$ \\
\hline \multirow[t]{7}{*}{ Lacerta agilis } & Poland & Odolanów & 33 & $8 / 3$ & $32 / 10$ & K. lacazei \\
\hline & Slovakia & Tajba & 1 & $1 / 0$ & $1 / 0$ & - \\
\hline & & Svidník & 16 & $16 / 0$ & $16 / 0$ & - \\
\hline & & Martinské hole & 11 & $11 / 0$ & - & - \\
\hline & & Račkova dolina & 4 & $4 / 0$ & - & - \\
\hline & & Moškovec & 4 & $4 / 0$ & - & - \\
\hline & Romania & Lepşa & 5 & $5 / 0$ & $5 / 1$ & - \\
\hline L. agilis ssp. exigua & Romania & Vadu & 20 & $20 / 2$ & $20 / 11$ & Karyolysus sp.* \\
\hline L. agilis ssp. erythronota & Romania & Vadu & 1 & $1 / 0$ & $1 / 1$ & - \\
\hline \multirow[t]{7}{*}{ L.viridis } & Slovakia & Burda & 91 & $91 / 0$ & $24 / 0$ & - \\
\hline & & Zádiel & 136 & $136 / 0$ & $14 / 0$ & - \\
\hline & & Tajba & 36 & $36 / 12$ & $9 / 1$ & K. latus \\
\hline & & Krupinská planina & 2 & $2 / 0$ & $2 / 1$ & - \\
\hline & Hungary & Gödöllő & 69 & $69 / 52$ & $36 / 17$ & K. lacazei \\
\hline & & Pilis & 7 & $7 / 1$ & $7 / 3$ & Karyolysus sp.* \\
\hline & Romania & Babadag & 3 & $3 / 0$ & $3 / 1$ & - \\
\hline L. viridis ssp. meridionalis & Romania & Deniz Tepe & 1 & $1 / 0$ & $1 / 0$ & - \\
\hline L. trilineata dobrogica & Romania & Sâcele & 10 & $10 / 6$ & $10 / 5$ & K. lacazei \\
\hline \multirow[t]{6}{*}{ Zootoca vivipara } & Poland & Odolanów & 16 & $5 / 0$ & $11 / 3$ & Karyolysus sp. \\
\hline & Slovakia & Ružín & 1 & $1 / 1$ & - & K. lacazei \\
\hline & & Zuberec & 17 & $17 / 0$ & - & - \\
\hline & & Račkova dolina & 11 & $11 / 0$ & - & - \\
\hline & & Martinské hole & 2 & $2 / 0$ & - & - \\
\hline & Romania & Vrancea & 2 & $2 / 2$ & $1 / 0$ & K. latus \\
\hline \multirow[t]{3}{*}{ Podarcis muralis } & Slovakia & Krupinská planina & 39 & $39 / 26$ & $10 / 10$ & K. latus \\
\hline & & Filakovo & 10 & $10 / 10$ & - & K. latus \\
\hline & Hungary & Pilis & 9 & $8 / 1$ & $7 / 0$ & K. latus \\
\hline TOTAL & & 20 & 557 & $520 / 116$ & $210 / 64$ & - \\
\hline PREVALENCE & & & & $22.3 \%$ & $30.5 \%$ & - \\
\hline
\end{tabular}

For each species, the total number of individuals tested, infected and species of parasites found are given, using microscopy or through PCR amplification. Asterisks indicate smears, where identification of parasite species was unsuccessful because of low parasitemia observed. 
negative. Mean length $(\mathrm{Ml})$ and mean width $(\mathrm{Mw})$ of various parasite stages and their nuclei found in positive smears were measured at $\times 1000$ magnifications.

A total of 520 individuals comprising of 8 species of lizards were examined for blood parasites. Details are given in Table 1.

\section{DNA extraction, amplification and sequencing}

DNA isolation (blood or tissue) was carried out using a commercial kit (NucleoSpin Blood and Tissue, MachereyNagel, Düren, Germany) according to the manufacturer's protocol. Isolated DNA was stored at $-20^{\circ} \mathrm{C}$.

PCR reactions were run in a $25 \mu \mathrm{l}$ reaction mixture from the Taq DNA Polymerase kit (Qiagen, Hilden, Germany) containing $2.5 \mu \mathrm{l} 10 x \mathrm{PCR}$ Coral Load PCR Buffer (15 pmol/ $\mu \mathrm{l} \mathrm{MgCl}$ ); $1 \mu \mathrm{l} \mathrm{MgCl} 2(25 \mathrm{pmol} / \mu \mathrm{l}) ; 0.5 \mu \mathrm{l}$ dNTPs $(10 \mathrm{pmol} / \mu \mathrm{l}) ; 0.5 \mu \mathrm{l}$ of each primer $(10 \mathrm{pmol} / \mu \mathrm{l})$ (Integrated DNA Technologies, Leuven, Belgium); $0.125 \mu \mathrm{l}$ Taq DNA Polymerase (5 U/ $\mu \mathrm{l}) ; 14.875 \mu \mathrm{l}$ water for molecular biology (Water, Mol Bio grade DN-ase, RN-ase, and Protease-free; 5Prime, Hamburg, Deutschland) and $5 \mu \mathrm{l}$ of DNA. Verification that the isolated DNA was appropriate for PCR amplification was assessed using primers, which amplify the $12 \mathrm{~S}$ rRNA [23]. Molecular detection of blood parasites was made by PCR reactions with HEPF300 (5' GTT TCT GAC CTA TCA GCT TTC GAC G 3')/ HEP900 (5' CAA ATC TAA GAA TTT CAC CTC TGA C 3') [24] and HEMO1 (5' TAT TGG TTT TAA GAA CTA ATT TTA TGA TTG 3')/HEMO2 (5' CTT CTC CTT CCT TTA AGT GAT AAG GTT CAC 3’) [25] primers targeting part of the 18S rRNA gene. The prepared mix was preheated to $95^{\circ} \mathrm{C}$ for $5 \mathrm{~min}$. Amplification with HEP300/HEP900 primers was performed as described by Ujvari et al. [26], but with an annealing temperature of $51^{\circ} \mathrm{C}$, while annealing temperature with HEMO1/HEMO2 primers was set to $48.8^{\circ} \mathrm{C}$.

In each PCR reaction negative (Water, Mol Bio grade DN-ase, RN-ase, and Protease-free; 5Prime, Hamburg, Deutschland) and positive (already sequenced sample) controls were included. Amplicons were separated on a 1.5\% agarose gel (Sigma-Aldrich, Buchs, Switzerland) in $1 \times \mathrm{TAE}$ Buffer (40 mM Tris, pH 7.8, $20 \mathrm{mM}$ acetic acid, $2 \mathrm{mM}$ EDTA). The gel was stained by Good View nucleic acid stain (Ecoli, Bratislava, Slovak republic) and afterwards was visualized using a UV transilluminator. Obtained positive PCR products (approximately $600 \mathrm{bp}$ ) were purified by GenElute $^{\text {tr }}$ PCR Clean-Up Kit (Sigma-Aldrich, Buchs, Switzerland) and sequenced by a commercial sequencing facility (University of Veterinary Medicine, Košice, Slovak republic), with all fragments sequenced in both directions.

\section{Phylogenetic analyses}

Sequences were visualized, edited using MEGA 4 and checked by eye. Checked sequences were compared to the sequences available in GenBank by using the basic local alignment search tool (BLASTn 2.2.26) and all of them matched with sequences of Hepatozoon sp. from various hosts. Based on Tomé et al. [22], related Hepatozoon sequences were downloaded and aligned using Clustal W. The final alignment consisted of 93 individuals, with 584 bps.

Maximum Likelihood (ML) analysis with random sequence addition was used to estimate evolutionary relationships using PhyML [26]. Support for nodes was estimated using the bootstrap technique [27] with 100 replicates. The model of evolution employed was chosen using the AIC criteria carried out in Modeltest 3.06 [28]. Bayesian analysis was implemented using Mr. Bayes v.3.2 [29] with parameters estimated as part of the analysis. The analysis was run for 10,000,000 generations, saving one tree every 1,000 generations. The loglikelihood values of the sample point were plotted against the generation time and all the trees prior to reaching stationary were discarded as burn-in samples. Remaining trees were combined in a $50 \%$ majority consensus tree. Haemogregarina balli Paterson and Desser, 1976 and Dactylosoma ranarum Lankester, 1882 were used as outgroups following Barta et al. [19].

To facilitate visualization of the phylogenetic relationships within the lineage including our isolates, a network was made using a region of $455 \mathrm{bp}$ of isolates from this lineage. The network was produced using a MedianJoining analysis with default parameters in software Network 4.6.1.0 [30].

\section{Results}

\section{Microscopic examination}

A total of 520 blood smears representing 4 species and 4 subspecies of lizards from different localities, were examined: 381 samples from Slovakia (36 Lacerta agilis, 265 L. viridis, 31 Zootoca vivipara and 49 Podarcis muralis), 84 from Hungary (76 L. viridis and 8 P. muralis), 42 from Romania $(5 \mathrm{~L}$. agilis, $20 \mathrm{~L}$. agilis ssp. exigua, 1 L. agilis ssp. erythronota, 3 L. viridis, 1 L. viridis ssp. meridionalis, $10 \mathrm{~L}$. trilineata ssp. dobrogica and $2 \mathrm{Z}$. vivipara) and 13 from Poland $(8 \mathrm{~L}$. agilis and $5 \mathrm{Z}$. vivipara).

The presence of protozoan parasites localized in red blood cells was observed in 116 samples, including $3 \mathrm{~L}$. agilis from Poland, $2 L$ agilis ssp. exigua from Romania, 12 L. viridis from Slovakia, 53 L. viridis from Hungary, 6 $L$. trilineata ssp. dobrogica from Romania, one $Z$. vivipara from Slovakia, $2 Z$. vivipara from Romania, 36 P. muralis from Slovakia and one P. muralis from Hungary (22.3\% prevalence) (Table 1).

Two species of Karyolysus, K. latus and K. lacazei, were identified based on morphology, measurements of 


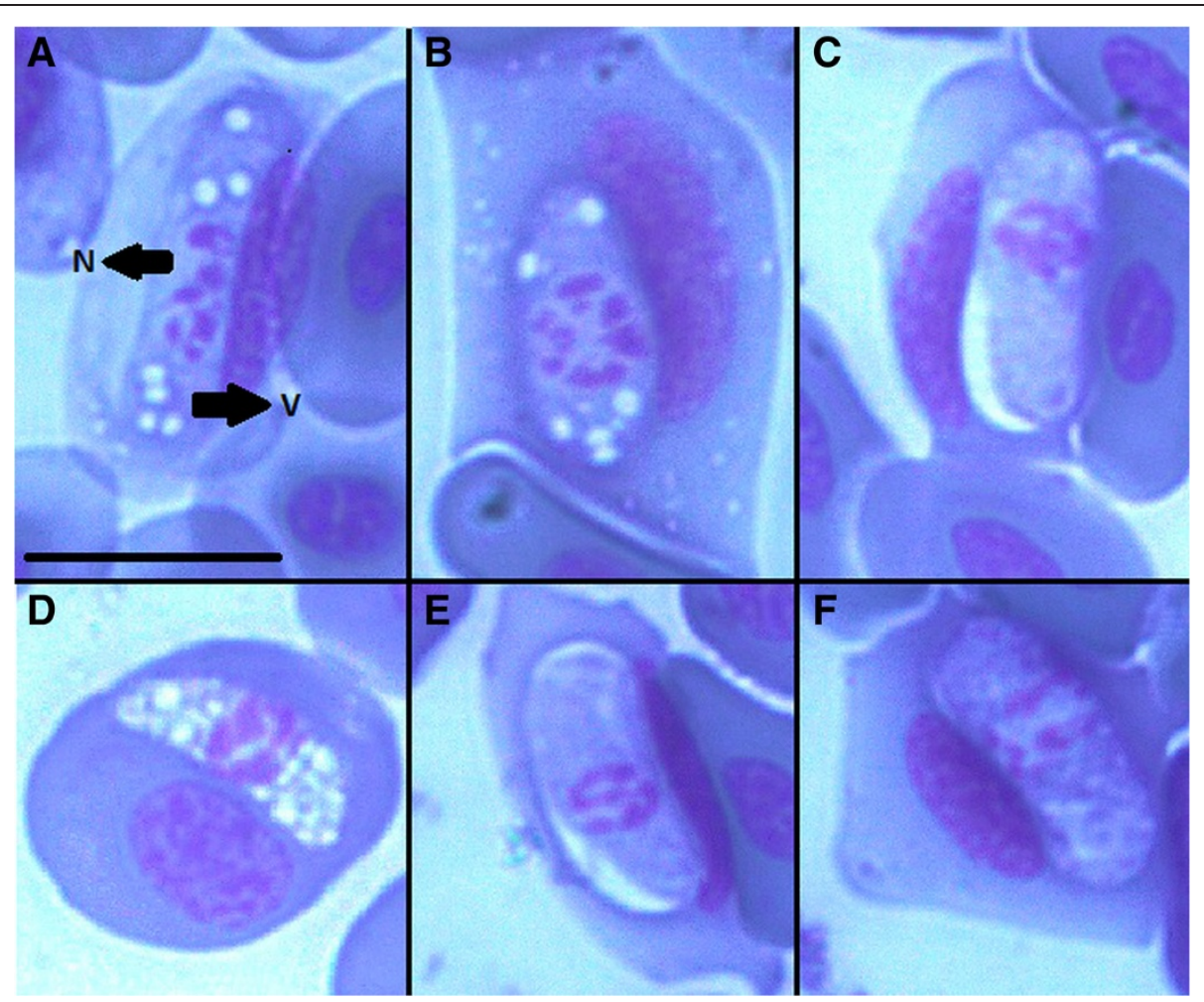

Figure 2 Karyolysus latus A-B and D trophozoites in blood smear of Podarcis muralis, C and E-F gamonts, C and E microgamonts, F macrogamonts. Arrows indicates organelles: $\mathrm{V}=$ vacuoles, $\mathrm{N}=$ nucleus, $\mathrm{Ma}=$ macrogamonts, $\mathrm{Mi}=$ microgamonts; scalebar $=10 \mu \mathrm{m}$.

the of parasite, as well as measurements of the parasite's nuclei as described by Svahn [4].

$K$. latus was found to infect $P$. muralis in Krupinská planina and $L$. viridis from Tajba. Trophozoites (Ml $11.40 \mu \mathrm{m}$, Mw $5.10 \mu \mathrm{m}$ ) found in blood smears were oval shaped, lentiform or beanshaped with pale vacuolated cytoplasm and a large diffuse reticulated centrally placed nucleus (Ml $3.80 \mu \mathrm{m}, \mathrm{Mw} 4.20 \mu \mathrm{m}$ ) (Figure 2, A-B and D). Gamonts were also oval with rounded ends with non-vacuolated cytoplasm. A distinct space was observed surrounding the parasite within the red blood cell (Figure 2, C and E). Cytoplasm of macrogamonts (Ml $11.53 \mu \mathrm{m}, \mathrm{Mw} 4.83 \mu \mathrm{m}$ ) stained dark blue, with a diffuse nucleus ( $\mathrm{Ml} 3.63 \mu \mathrm{m}, \mathrm{Mw}$ $4.10 \mu \mathrm{m}$ ), located centrally (Figure 2, F). Microgamonts
(Ml $11.93 \mu \mathrm{m}, \mathrm{Mw}$ 4.97) stained light blue and the nuclei (Ml $3.63 \mu \mathrm{m}, \mathrm{Mw} 4.07 \mu \mathrm{m}$ ) were more compact (Figure 2, $\mathrm{C}$ and $\mathrm{E}$ ). There is no capsule surrounding the gamonts.

Host cells were hypertrophied and their nuclei were displaced by the parasite. In most cases the nuclei of the host cells were elongated and compressed, pushed to one of the long sides of the parasite, sometimes displaced to one of the ends of parasite (Figure 2).

K. lacazei was identified in L. agilis in Poland, L. viridis in Hungary and L. trilineata ssp. dobrogica in Romania. Trophozoites are thin and elongated, and the cytoplasm is vacuolated (Figure 3, A). It was not possible to distinguish micro and macrogamonts. The shape of the cells is slender and thin with one end bent. The cytoplasm of gamonts

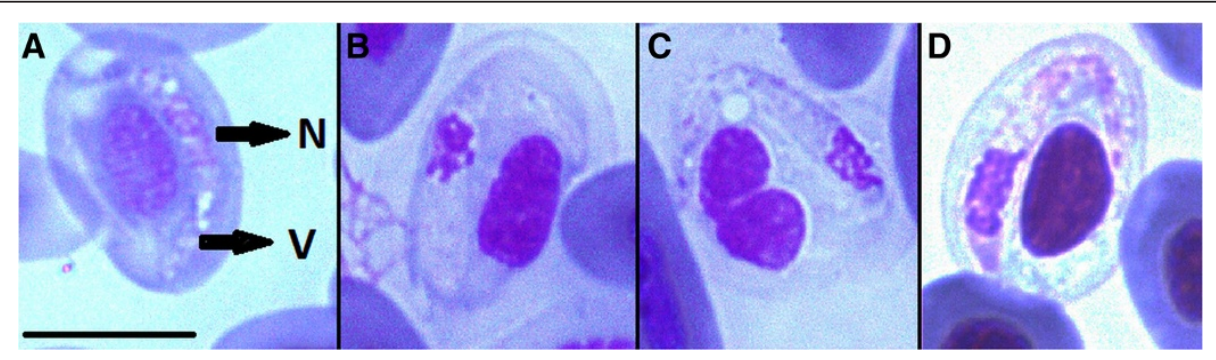

Figure 3 Karyolysus lacazei A trophozoite found in blood smear of Lacerta trilineata, Romania, B-D gamonts found in Lacerta viridis from Hungary. Arrows indicates organelles: $V=$ vacuoles, $N=$ nucleus; scalebar $=10 \mu \mathrm{m}$. 
(Ml $20.69 \mu \mathrm{m}, \mathrm{Mw} 2.8 \mu \mathrm{m}$ ) stained pale blue, and vacuoles were not present. The position of the nucleus $(\mathrm{Ml} 4.68 \mu \mathrm{m}$, Mw 2.54 $\mu \mathrm{m}$ ) is shifted laterally, or placed at the distal end of the parasite (Figure 3, B - D). The presence of the parasite caused great changes in the appearance of the host cells, which was hypertrophied with cytoplasm observed with difficulty (loss of staining properties). The nuclei of infected hosts were swollen, sometimes compressed and darkly stained (Figure 3).

\section{Ectoparasites}

Two species of ectoparasites on collected lizards; protonymphs and females of Ophionyssus saurarum mites (Figure 4) and larvae and nymphs of I. ricinus ticks, were identified. Prevalence of infestation with developmental stages (larvae, nymphs) of $I$. ricinus ticks ranged from $52.4 \%$ to $75.6 \%$. Compared with ticks, mites were not collected in great quantities, so we did not reveal prevalence of infestation.

\section{Developmental stages in mites}

Smears of mites contained several free gamonts released from erythrocytes after blood sucking. Sporokinetes were found in the hemocoel of Ophionyssus mites (Figure 5, A and C) as well as from the clutch of eggs prepared immediately after oviposition (Figure 5, B). They had a pale blue cytoplasm with few but large vacuoles. The nucleus was located centrally or pericentrally with various appearances rather diffuse without a clear boundary (Figure 5).

\section{Molecular analysis}

Only amplicons using the HEP300/HEP900 primers yielded usable DNA sequences of approximate $580 \mathrm{bps}$. Out of 210 DNA samples (54 L. agilis, 20 L. agilis ssp. exigua, one L. agilis ssp, erythronota, 95 L. viridis, one L. viridis ssp. meridionalis, 10 L. trilineata ssp. dobrogica,
12 Z. vivipara and 17 P. muralis), the fragment of Karyolysus sp. 18S rRNA was amplified in 64 (the prevalence of 30.5\%) samples by PCR: 20 lizards from Hungary (L. viridis), 19 from Romania (one L. agilis, 11 L. agilis ssp. exigua, one $L$. agilis ssp, erythronota, one $L$. viridis and 5 L. trilineata ssp. dobrogica), 13 from Poland (10 L. agilis and 3 Z. vivipara) and 12 from Slovakia (2 L. viridis and $10 \mathrm{P}$. muralis) (Table 1 ). Eight isolates (five isolates of Karyolysus sp. 18S rRNA from lizards and 3 from ectoparasites) deposited in GenBank were used for phylogenetic analyses, including isolates of $K$. lacazei 18S rRNA from L. viridis (Hungary; KJ461943), L. agilis (Poland; KJ461940) and L. trilineata ssp. dobrogica (Romania; KJ461942); K. latus 18S rRNA from P. muralis (Slovakia; KJ461939) and Karyolysus sp. 18S rRNA from Z. vivipara (Poland; KJ461946). Besides lizards we also amplified the fragment of Karyolysus sp. 18S rRNA in I. ricinus and $O$. saurarum collected from lizards. For phylogenetic analyses three isolates of Karyolysus sp. $18 \mathrm{~S}$ rRNA from these final hosts were used; from $O$. saurarum collected from Z. vivipara (Poland; KJ461945) and L. viridis (Hungary; KJ461944) and in a nymph of I. ricinus tick collected from L. viridis (Hungary; KJ461941). Details concerning GenBank accesion numbers are given in Additional file 1.

\section{Phylogenetic analysis}

Phylogenetic analyses (Bayesian method and Maximum Likelihood) gave the same overall estimate of phylogenetic patterns. Comparison of the eight isolates revealed the existence of four haplotypes, all part of the same lineage within sequences of parasites derived from North African lizards and snakes (Figure 6).

The first haplotype is represented by a parasite isolated from P. muralis (Slovakia, Krupina plateau). The second haplotype was identified from five isolates, including parasites from Z. vivipara (Poland), L. viridis (Hungary),

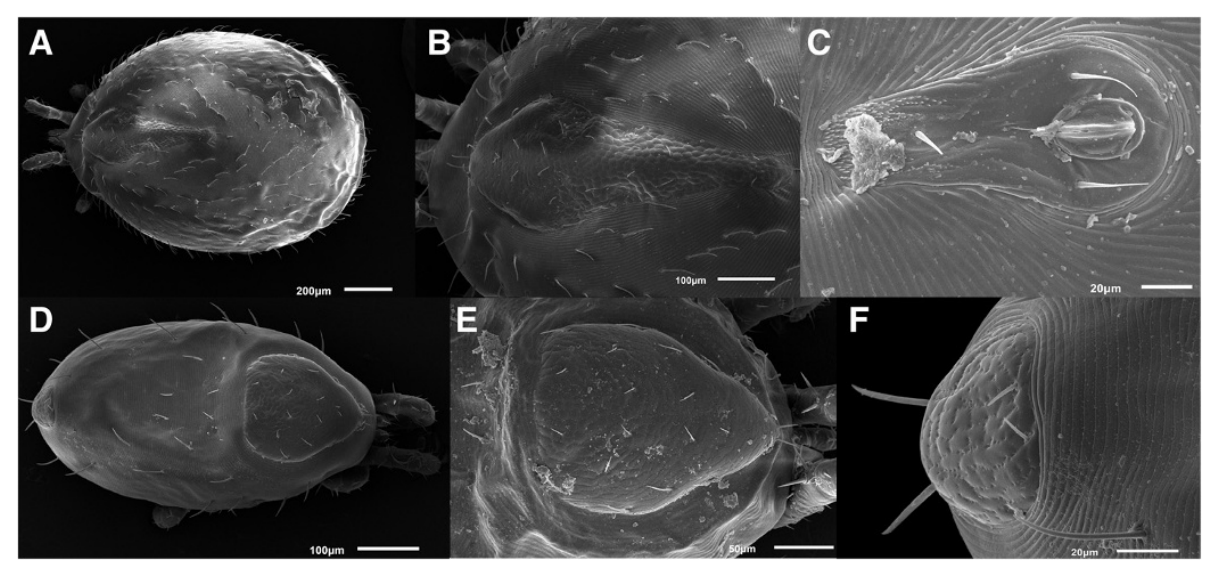

Figure 4 Ophionyssus saurarum A-C female of $O$. saurarum, D-F protonymph of $O$. saurarum; A and D dorsal view, B dorsal shield E podonotal shield $C$ anal shield, $F$ pygidial shield. 


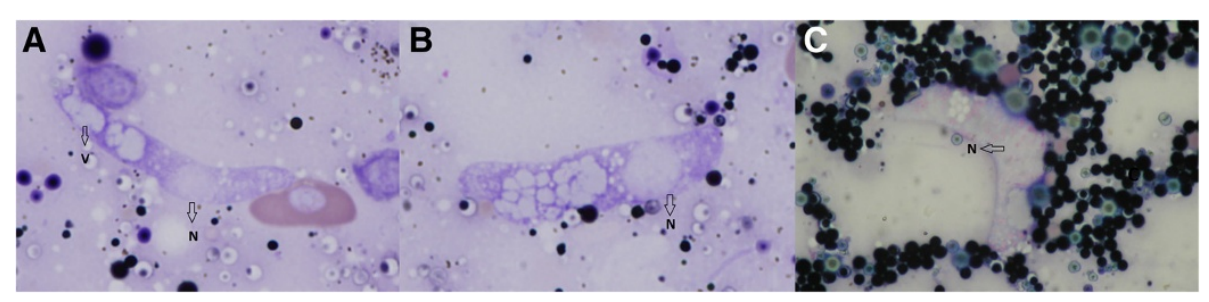

Figure 5 Karyolysus sp. found in Ophionyssus mites. A sporokinete from the hemocoel of nymph of Ophionyssus found on wall lizard, Čabrad', B sporokinete from the clutch of eggs of Ophionyssus mite, $\mathbf{C}$ sporokinete from the smear of Ophionyssus mite found on green lizard, Tajba. Arrows indicates organelles: $\mathrm{V}=$ vacuoles, $\mathrm{N}=$ nucleus.

L. trilineata ssp. dobrogica (Romania), O. saurarum collected from $Z$. vivipara (Poland) and I. ricinus from $L$. viridis (Hungary). The third haplotype is represented by parasite from L. agilis (Poland). The first, the second and the third haplotypes are closely related to parasites found in P. vaucheri from North Africa. Finally, the fourth haplotype is represented by the DNA sequence of the parasite isolated from $O$. saurarum from $L$. viridis (Hungary) and related to African parasites from T. tangitanus and Atlantolacerta andreanskyi.

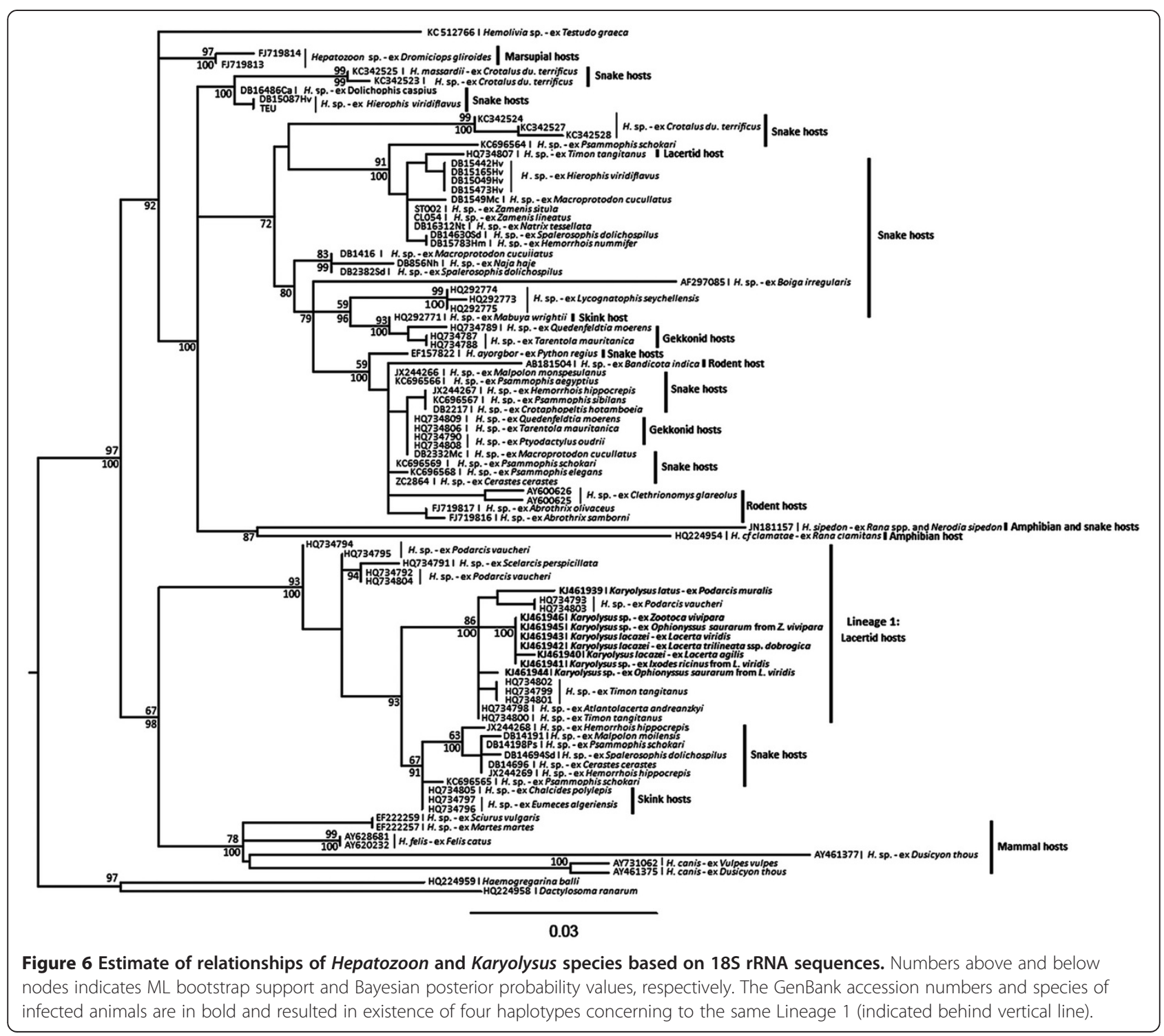


Within the lineage 1 , containing our isolates analyzed by Median-Joining Network, the majority of haplotypes obtained in this study (Z. vivipara, L. viridis, L. trilineata ssp. trilineata, O. saurarum from $Z$. vivipara, $I$. ricinus from $L$. viridis and $L$. agilis) formed a group, whereas Karyolysus parasites from $P$. muralis and $O$. saurarum from L. viridis were slightly genetically distinct (Figure 7). However, there was no association between the two morphologically identified species and the genetic relationships.

\section{Discussion and conclusions}

Apicomplexan blood parasites represent a group of uniand intra-cellular parasites, which can parasitize various species of animals with a worldwide distribution. We have only limited information about the presence of blood parasites in European reptiles, while even less is known about their molecular characterization. To the best of our knowledge this study represents the first assessment of genetic diversity of these parasites found in Central-Eastern European lizards.

Examined lizards were collected from twenty localities from four European countries (Hungary, Poland, Slovakia and Romania). Although we have scarce information about the prevalence of blood parasites found in reptiles from Poland and Romania, molecular detection of these parasites from European reptiles, collected in the abovementioned countries, has never been performed.

Previously there was only information about the presence of blood parasites in L. viridis, L. agilis agilis, L. a. chersonensis, Z. vivipara, E. orbicularis and Testudo graeca ibera $[2,9]$. In Hungary, blood parasites of reptiles have been studied only on a small population of green lizards ( 25 individuals) [15]. In this study we identified haplotypes of blood parasites from all studied countries for the first time.

Overall prevalence of blood parasites in blood smears was $22.3 \%$, but prevalence of infection between localities varied. We examined 13 individuals from Poland, and parasites were found in three animals (prevalence of 23.1\%). Although representative sampling was quite low, results are comparable with $29.4 \%$ prevalence detected by Majláthová et al. [9]. For lizard species from Romania, parasites were observed in 10 individuals from 42 examined (prevalence of 23.8\%), which is quite low in comparison with prevalence of $60.71 \%$ and $100 \%$ respectively, detected by Mihalca et al. [2]. A total of 84 green lizards (L. viridis) from Hungary were examined with 54 smears found to contain blood parasites (prevalence of $64.3 \%$ ) in comparison with $96 \%$ prevalence found by Molnár et al. [15].

Although we examined reptiles from twelve different habitat types in Slovakia, blood parasites were detected only in four localities: Tajba, Krupinská planina, Filakovo castle ruins and near the water basin Ružín. These areas are localized mainly in the Southern part of Slovakia, where we can assume higher temperature during the year, which may be important for parasite development [4]. One exception represents the southernmost studied locality (Burda), where parasites were not found. On the other hand, Odolanów (Poland) is situated to the north of Slovakia, but the prevalence of blood parasites in the studied reptiles was relatively high [9]. Besides temperature as one of the key factors for the variable occurrence of blood parasites at our localities, altitude may also be important. Areas in Slovakia with presence of blood parasites are localized between $100-320$ m. a. s. 1., as well as areas in Poland (110 m. a. s. 1.) and Hungary (124 and 211 m. a. s. 1., respectively), whereas in reptiles from Romania from lower altitude were infected $(15-200 \mathrm{~m}$. a. s. 1.). Other studies from Slovakia are situated between $380-1500 \mathrm{~m}$. a. s. 1., where conditions are probably less favorable for parasite development [4], although we observed the presence of ectoparasites on reptiles collected from the same locality. Contrarily, blood parasites found in lizards from

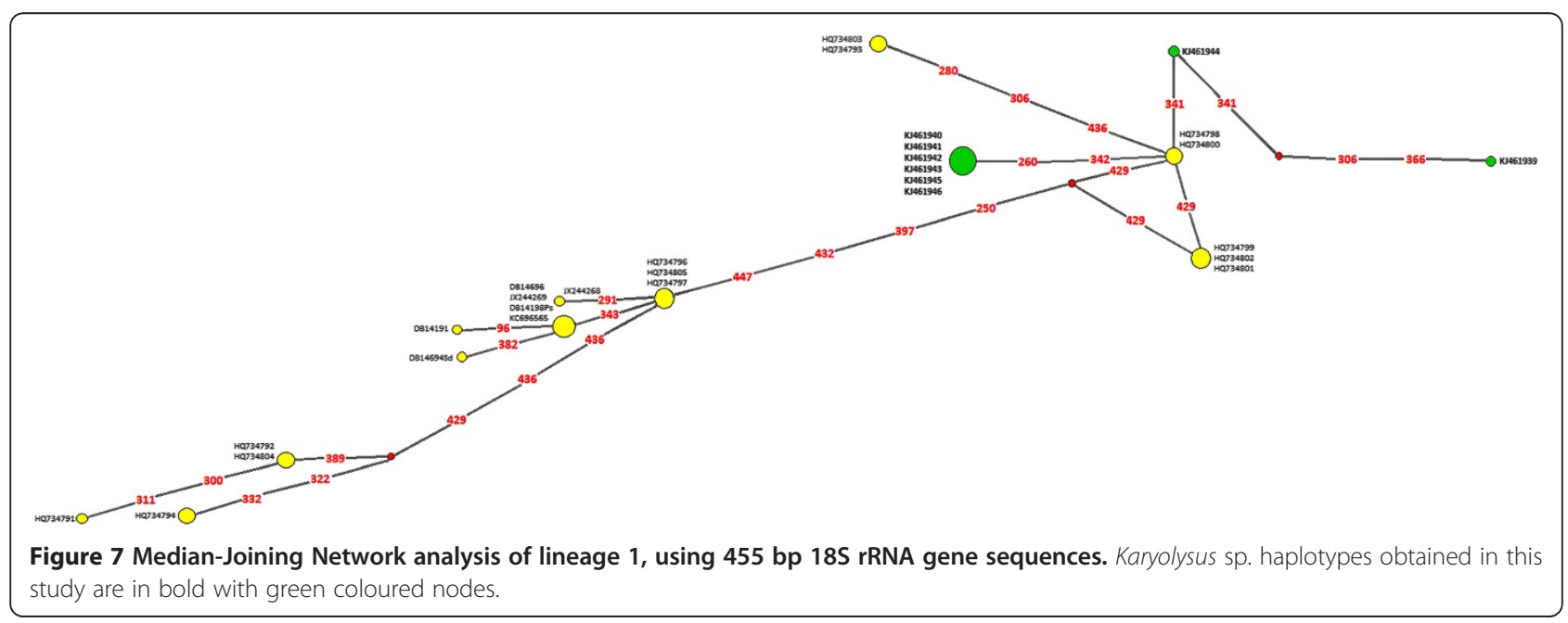


southern part of Europe at higher altitudes from 650 $2,200 \mathrm{~m}$. a. s. l. have been detected [3,12-14,16-18].

Smears of mites collected from lizards contained several free gamonts released from erythrocytes after bloodsucking, and moreover sporokinetes were also found in the smear preparations from the mite eggs. The same results were observed only twice before, in mites collected from Scandinavian lizards $[4,5]$. These results showed that mites of Ophionyssus sp. serve as vectors for Karyolysus sp. in Europe, as demonstrated by experimental transmission and finding of sporokinets in mite's eggs, which confirmed the presence of Karyolysus sp., because this genus of blood parasite is characterized by transstadial and transovarial transmission [5]. Except for this study, only the reptile intermediate hosts have been examined in Europe by microscopic observations, mainly in the Mediterranean region [11-14,16]. One of the life cycle differences between Karyolysus, Hepatozoon and Hemolivia is transovarial transmission which was not described in Hepatozoon or Hemolivia but occurs in Karyolysus and we observed it as well.

Phylogenetic analysis showed that isolates obtained in this study fall within the same lineage with sequences of parasites originating from North African reptiles, which were identified as Hepatozoon sp. [31]. The lineage containing isolates obtained in this study differs on one hand from sequences of Hepatozoon parasites isolated from African geckos (Ptyodactylus sp., Quedenfeldtia sp. and Tarentola sp.), snakes (Python regius, Boiga irregularis and Lycognatophis seychellensis) and rodents (Clethrionomys sp. and Abrothrix sp.) from Chile, Spain and Thailand, and on the other hand from Hepatozoon isolates primarily from dogs and cats. Previously, Karyolysus has never been characterized by molecular methods [2-5]; identification of Karyolysus in reptile species was based on microscopic methods only. Current taxonomy is greatly complicated by the identification of parasites by a limited number of morphological attributes, which are clearly not consistent. Thus the genus Karyolysus, as the Greek name implies, was first proposed for hemogregarines that distort the host cell nucleus. However, "karyolysing hemagregarines" such as ones identified in Algerian lacertids, Timon sp., are now classified as Hepatozoon curvirostris, and not Karyolysus. Not only this, but apparent Karyolyus species identified in this study are genetically related to forms from Iberian and North African reptiles in which deformation of the host nucleus was not reported [18]. At the same time other characters are applied haphazardly for identification of parasites - gamonts are identified as Karyolysus due to the vertebrate host they are found in, or "probably" to Hepatozoon when the same hosts, $P$. muralis, are heavily infected with ticks for example [3]. Furthermore the same genetic lineage of parasites is found in this study in both ticks and mites. It is clear therefore that no simple alteration to taxonomy will resolve the issue. Identifying the whole genetic lineage (1) as Karyolysus would mix forms that apparently both do and do not distort the host nucleus. However, any other arrangement would make Hepatozoon paraphyletic. Since new lineages are regularly being identified, for example in birds [32], or caecilians [20] it also seems premature to rearrange the nomenclature, since new discoveries will almost certainly alter our understanding of evolutionary relationships of these parasites [33]. A similar situation arises regarding the genus Hemolivia, which also appears to be part of the same major group with Hepatozoon and Karyolysus, and for which relationships vary depending on the out-groups employed $[21,34]$. Although the sequences used in this study are quite short (584 bp), this issue is unlikely to be resolved with a longer fragment of $18 \mathrm{~S}$ rRNA, since [18] already demonstrated that estimates of relationships based on this short fragment were the same as those based on the longer fragment employed in some other studies. However, the slow-evolving nature of the marker may be part of the problem in observing differences between the two morphologically identified species. Faster evolving genes may be necessary to disentangle relationships at the species level.

Although the result of phylogenetic analysis placed Karyolysus sp. isolates obtained in this study within Hepatozoon making this genus paraphyletic $[19,21,35,36]$, we can observe differences in biology of these two genera of parasites. Hepatozoon is transmitted via ingestion of a wide spectrum of invertebrates (ixodid and argasid ticks, triatomid bugs, leeches, flies, sucking lice, fleas, sandflies and mosquitoes) [37] and is characterized by polysporocystic oocysts formed in hemocoel of the abdomen, thorax or within the head of final host [1,37]. Moreover transovarial transmission of the Hepatozoon in definitive invertebrate hosts has never been demonstrated [38-40]. On the contrary, the only final invertebrate host identified for the Karyolysus sp. is represented by mites of the genus Opionyssus $[1,4,5]$. Karyolysus is also characterized by sporozoites within oocysts localized in the gut cells of the final host $[1,19]$ as well as transovarial transmission within the final host have also been observed [1,4,5]. Based on the results we can conclude that molecular data available are insufficient to reveal actual position of Karyolysus sp. with/within Hepatozoon sp.

This work represents the first molecular insight to the phylogeny of Karyolysus sp. found in studied reptile species collected in various localities of Central-Eastern Europe. Previously, species of Karyolysus were detected primarily using morphological characteristics of gamonts found in infected reptile hosts. Our study indicates this is unsatisfactory, and that the incorporation of molecular data has clear advantages. The combined approach used in this study could reveal further discrepancies in the 
actual classification, and we suggest is enlarged to include additional geographic regions and other potential reptile intermediate hosts of these poorly-known parasites.

\section{Ethical approval for animal use}

Capturing lizards and sample collection were carried out with official permission from the Middle Danube Valley Inspectorate for Environmental Protection, Nature Conservation and Water Management (Hungary), 6103/2007-2.1 and 5498/2011-2.2 issued by the Ministry of Environment of the Slovak Republic, and 12/2007 issued by the local ethics committee for animal studies in Poznań (Poland).

\section{Additional file}

Additional file 1: The GenBank accession numbers of Karyolysus samples obtained in this study.

\section{Competing interests}

The authors declare that they have no competing interests.

\section{Authors' contributions}

$\mathrm{BH}-\mathrm{K}$ analyzed collected samples and blood smears, performed PCR and wrote the manuscript; IM and VM designed the study, collected material and assisted in writing the manuscript; $\mathrm{AH}, \mathrm{NK}$ and BM contributed samples and assisted in analyzing of blood smears; DJH performed phylogenetic analyses and assisted in writing a manuscript; KR, GF and PT contributed samples and helped to improve the manuscript. All authors read and approved the final version of the manuscript.

\section{Acknowledgments}

Thanks to our colleagues, M. Bona, M. Hromada and T. Sahlean who helped with the field work. Thanks to colleague, D. Barčák who helped with the photography of mites. This work was financially supported by the project Environmental protection against parasitozoonoses under the influence of global climate and social changes (code IMTS: 26220220116), supported by the Research \& Development Operational Programme funded by the ERDF (0.5), ITMS: 26110230045 and by the Scientific Grant Agency of the Ministry of Education of Slovak Republic and the Slovak Academy of Sciences VEGA $1 / 0417 / 14$ and is co-financed by the European Social Fund and the state budget of the Czech Republic project no. CZ.1.07/2.3.00/30.0022. G. F. was supported by the János Bolyai Research Scholarship of the Hungarian Academy of Sciences and NKB and Research Faculty grants from the Faculty of Veterinary Science, Szent István University. This study was conducted under the frame of the EurNegVec COST Action TD1303.

\section{Author details}

${ }^{1}$ Institute of Parasitology, Slovak Academy of Sciences, Hlinkova 3, 04001 Košice, Slovak Republic. ${ }^{2}$ Institute of Biology and Ecology, University of P. J. Šafárik in Košice, Moyzesova 11, 04001 Košice, Slovak Republic. ${ }^{3}$ Department of Parasitology, State Veterinary Institute Jihlava, Rantírovská 93, 58605 Jihlava, Czech Republic. ${ }^{4} \mathrm{Cl}-\mathrm{BIO}-U P$, Centro de Investigação em Biodiversidade e Recursors Genéticos da Universidade do Porto, Campus Agrário de Vairão, 4485-661 Vairão, Portugal. ${ }^{5}$ Department of Parasitology and Zoology, Faculty of Veterinary Science, Szent István University, 2 István Street, Budapest H-1078, Hungary. ${ }^{6}$ Institute of Zoology, Poznań University of Life Sciences, Wojska Polskiego 71 C, 60-625 Poznań, Poland. ${ }^{7}$ Department of Biochemical Sciences, Charles University in Prague, Faculty of Pharmacy in Hradec Kralove, Hradec Kralove, Czech Republic.

Received: 7 August 2014 Accepted: 22 November 2014 Published online: 10 December 2014

\section{References}

1. Telford SR: Hemoparasites of Reptilia, Color Atlas and Text. Boca Raton, Florida, USA: CRC Press, Taylor \& Francis Group; 2009.
2. Mihalca AD, Racka K, Gherman C, lonescu DT: Prevalence and intensity of blood apicomplexan infections in reptiles from Romania. Parasitol Res 2008, 102(5):1081-1083.

3. Hassl AR: Blood parasitism by hemogregarines in Central European lizards. Herpetozoa 2012, 25(1-2):83-86.

4. Svahn K: Blood parasites of the genus Karyolysus (Coccidia, Adeleidae) in Scandinavian lizards. Description and life cycle. Norw J Zool 1975, 23:277-295.

5. Svahn K: Incidence of blood parasites of the genus Karyolysus (Coccidia) in Scandinavian lizards. Oikos 1974, 25:43-53.

6. Beyer TV, Sidorenko NV: Karyolysus sp. (Haemogregarinidae, Adeleida, Apicomplexa): Host-Parasite Relationships of Persisting Stages. J Protozool 1984, 31(4):513-517.

7. Gwiazdowicz DJ, Filip KP: Ophionyssus saurarum (Acari, Mesostigmata) infecting Lacerta agilis (Reptilia, Lacertidae). Wiad Parazytol 2009, 55(1):61-62.

8. $\quad$ Siuda K: Kleszcze (Acari: Ixodida) Polski. I. Warszawa: Wiadomości ogólne; 1991.

9. Majlathova V, Majlath I, Haklova B, Hromada M, Ekner A, Antczak M, Tryjanowski P: Blood parasites in two co-existing species of lizards (Zootoca vivipara and Lacerta agilis). Parasitol Res 2010, 107(5):1121-1127.

10. Telford SR, Moler PE, Butlert JF: Hepatozoon species of the timber rattlesnake in northern Florida: Description of a new species, evidence of salivary gland oocysts, and a natural cross-familial transmission of an Hepatozoon species. J Parasitol 2008, 94(2):520-523.

11. Garrido M, Perez-Mellado V: Prevalence and intensity of blood parasites in insular lizards. Zool Anz 2013, 252(4):588-592.

12. Amo L, Fargallo JA, Martinez-Padilla J, Millan J, Lopez P, Martin J: Prevalence and intensity of blood and intestinal parasites in a field population of a Mediterranean lizard, Lacerta lepida. Parasitol Res 2005, 96(6):413-417.

13. Amo L, Lopez P, Martin J: Prevalence and intensity of haemogregarinid blood parasites in a population of the Iberian rock lizard, Lacerta monticola. Parasitol Res 2004, 94(4):290-293.

14. Amo L, Lopez P, Martin J: Prevalence and intensity of haemogregarine blood parasites and their mite vectors in the common wall lizard, Podarcis muralis. Parasitol Res 2005, 96(6):378-381.

15. Molnar O, Bajer K, Meszaros B, Torok J, Herczeg G: Negative correlation between nuptial throat colour and blood parasite load in male European green lizards supports the Hamilton-Zuk hypothesis. Naturwissenschaften 2013, 100(6):551-558.

16. Roca V, Galdon MA: Haemogregarine blood parasites in the lizards Podarcis bocagei (Seoane) and P. carbonelli (Perez-Mellado) (Sauria: Lacertidae) from NW Portugal. Syst Parasitol 2010, 75(1):75-79.

17. Harris DJ, Maia JPMC, Perera A: Molecular Survey of Apicomplexa in Podarcis Wall Lizards Detects Hepatozoon, Sarcocystis, and Eimeria Species. J Parasitol 2012, 98(3):592-597.

18. Maia JPMC, Perera A, Harris DJ: Molecular survey and microscopic examination of Hepatozoon Miller, 1908 (Apicomplexa: Adeleorina) in lacertid lizards from the western Mediterranean. Folia Parasit 2012 59(4):241-248

19. Barta JR, Ogedengbe JD, Martin DS, Smith TG: Phylogenetic position of the adeleorinid coccidia (Myzozoa, Apicomplexa, Coccidia, Eucoccidiorida, Adeleorina) inferred using 18s rDNA sequences. J Euk Microbiol 2012, 59(2):171-180.

20. Harris DJ, Damas-Moreira I, Maia JPMC, Perera A: First report of Hepatozoon (Apicomplexa: Adeleorina) in caecilians, with description of a new species. J Parasitol 2014, 100(1):117-120.

21. Kvičerová J, Hypša V, Dvořáková N, Mikulíček P, Jandzik D, Gardner MG, Javanbakht H, Tiar G, Široký P: Hemolivia and Hepatozoon: Haemogregarines with tangled evolutionary relationships. Protist 2014, 165(5):688-700.

22. Tomé B, Maia JP, Salvi D, Brito JC, Carretero MA, Perera A, Meimberg H, Harris DJ: Patterns of genetic diversity in Hepatozoon spp. infecting snakes from North Africa and the Mediterranean Basin. Syst Parasitol 2014, 87(3):249-258.

23. Humair PF, Douet V, Cadenas FM, Schouls LM, Van de Pol I, Gern L: Molecular identification of bloodmeal source in Ixodes ricinus ticks using 12S rDNA as a genetic marker. J Med Entomol 2007, 44(5):869-880.

24. Ujvari B, Madsen T, Olsson M: High prevalence of Hepatozoon spp (Apicomplexa, hepatozoidae) infection in water pythons (Liasis fuscus) from tropical Australia. J Parasito/ 2004, 90(3):670-672. 
25. Perkins SL, Keller AK: Phylogeny of nuclear small subunit rRNA genes of hemogregarines amplified with specific primers. J Parasitol 2001, 87(4):870-876.

26. Guindon S, Dufayard JF, Lefort V, Anisimova M, Hordijk W, Gascuel O: New algorithms and methods to estimate maximum-likelihood phylogenies: Assessing the performance of PhyML 3.0. Syst Biol 2010, 59(3):307-321.

27. Felsenstein J: Confidence-Limits on Phylogenies - an Approach Using the Bootstrap. Evolution 1985, 39(4):783-791.

28. Posada D, Crandall KA: MODELTEST: testing the model of DNA substitution. Bioinformatics 1998, 14(9):817-818.

29. Huelsenbeck JP, Ronquist F: MRBAYES: Bayesian inference of phylogenetic trees. Bioinformatics 2001, 17(8):754-755.

30. Bandelt HJ, Forster P, Röhl A: Median-joining networks for inferring intraspecific phylogenies. Mol Biol Evol 1999, 16(1):37-48.

31. Maia JP, Harris DJ, Perera A: Molecular survey of Hepatozoon species in lizards from North Africa. J Parasitol 2011, 97(3):513-517.

32. Quillfeldt $P$, Martínez J, Bugoni L, Mancini PL, Merino S: Blood parasites in noddies and boobies from Brazilian offshore islands-differences between species and influence of nesting habitat. Parasitology 2014, 141(3):399-410.

33. Baneth G, Sheiner A, Eyal O, Hahn S, Beaufils JP, Anug Y, Talmi-Frank D: Redescription of Hepatozoon felis (Apicomplexa: Hepatozoidae) based on phylogenetic analysis, tissue and blood form morphology, and possible transplacental transmission. Parasit Vectors 2013, 6:102.

34. Harris DJ, Graciá E, Jorge F, Maia JPMC, Perera A, Carretero MA, Giménez A: Molecular Detection of Hemolivia (Apicomplexa: Hameogregarinidae) from Ticks of North African Testudo graeca (Testudines: Testudinidae) and an Estimation of Their Phylogenetic Relationships Using 18S rRNA Sequences. Comp Parasitol 2013, 80(2):292-296.

35. Siddall ME: Phylogeny of adeleid blood parasites with a partial systematic revision of the haemogregarine complex. J Eukaryot Microbiol 1995, 42(2):116-125.

36. Smith TG, Kim B, Hong H, Desser SS: Intraerythrocytic development of species of Hepatozoon infecting ranid frogs: evidence for convergence of life cycle characteristics among apicomplexans. J Parasitol 2000, 86(3):451-458.

37. Smith TG: The genus Hepatozoon (Apicomplexa: Adeleina). J Parasitol 1996, 82(4):565-585.

38. Baneth G, Samish M, Alekseev E, Aroch I, Shkap V: Transmission of Hepatozoon canis to Dogs by Naturally-Fed or Percutaneously-Injected Rhipicephalus sanguineus Ticks. J Parasitol 2001, 87(3):606-611.

39. Johnson EM, Allen KE, Panciera RJ, Ewing SA, Little SE: Experimental transmission of Hepatozoon americanum to New Zealand White rabbits (Oryctolagus cuniculus) and infectivity of cystozoites for a dog. Vet Parasitol 2009, 164(2-4):162-166.

40. Giannelli A, Ramos RAN, Di Paola G, Mencke N, Torres FD, Baneth G, Otranto D: Transstadial transmission of Hepatozoon canis from larvae to nymphs of Rhipicephalus sanguineus. Vet Parasitol 2013, 196(1-2):1-5.

\section{Submit your next manuscript to BioMed Central and take full advantage of:}

- Convenient online submission

- Thorough peer review

- No space constraints or color figure charges

- Immediate publication on acceptance

- Inclusion in PubMed, CAS, Scopus and Google Scholar

- Research which is freely available for redistribution 